\title{
RE: Long-term efficacy of microbiology-driven periodontal laser-assisted therapy, by Martelli et al., Eur J Clin Microbiol Infect Dis 2016, 35(3): 423-431
}

\author{
C. Gatti $^{1} \cdot$ M. Aimetti ${ }^{1}$ - G. Rasperini ${ }^{1} \cdot$ L. Landi ${ }^{1}$ - F. Cairo ${ }^{1,2}$ - on behalf of SIdP, Italian \\ Society of Periodontology and Implantology
}

Received: 31 July 2016 / Accepted: 31 July 2016 /Published online: 13 October 2016

(C) The Author(s) 2016. This article is published with open access at Springerlink.com

Dear Editor,

We read with interest the manuscript by Dr Martelli et al. entitled "Long-term efficacy of microbiology-driven periodontal laser-assisted therapy" [1], recently published in the European Journal of Clinical Microbiology \& Infectious Diseases (2016 Mar; 35(3): 423-431). In this manuscript, the authors described the treatment of periodontal disease in more than 2,000 patients, and reported clinical and microbiological findings after 2 years. As board members of the Italian Society of Periodontology and Implantology (SIdP) we would like to draw attention to some critical points that may affect the study outcomes and conclusions.

\section{Diagnosis}

The diagnosis of periodontal disease as applied by the authors is far from the current international standard [2]. In the present manuscript, information with regard to mean clinical attachment level, full-mouth plaque score, full-mouth bleeding score and tooth loss is unknown. In addition, the diagnosis of severe periodontal disease applies when more than $30 \%$ of sites are involved in chronic periodontitis, while for aggres-

President SIdP — Claudio Gatti

Elected President SIdP — Mario Aimetti

Vice President SIdP — Giulio Rasperini

Treasurer SIdP — Luca Landi

General Secretary SIdP — Francesco Cairo

F. Cairo

cairofrancesco@virgilio.it; segretario@sidp.it

1 Viale dei Mille, 9, 50131 Firenze, Italy

2 via fra' G. Angelico 51, 50121 Firenze, Italy sive periodontitis this definition should be extended with the involvement of at least three additional teeth to molars/incisors. The definition of disease severity used by the authors is based on personal criteria. Furthermore, information with regard to possible risk factors for periodontal disease is limited to smoking habits only, although the detrimental effect of other risk factors or potential risk factors (such as diabetes, systemic diseases, immunodeficiency, drugs, osteoporosis, stress, obesity, etc.) in terms of disease progression and treatment outcomes is very well known [3].

\section{Treatment}

In the additional material section, the authors stated "An $a c$ curate mechanical ultrasound for SRP was performed according to the needs of the patients and up to complete satisfaction of the clinicians. After completion of SRP, patients were treated in all pockets with a $1064 \mathrm{~nm} \mathrm{Nd:YAG} \mathrm{laser"} \mathrm{[1].} \mathrm{This}$ means that classical mechanical sub-gingival debridement of root surfaces (SRP) was performed at each experimental site before laser application and the final delivered therapy is a combination of SRP and laser treatment. Since the study is a case series lacking a control group (single treatment with SRP or laser) it is impossible for the reader to assess if final benefits are associated or not with laser application. A randomized clinical trial (RCT) is mandatory to investigate the efficacy of combined therapy versus single treatments, and to understand the potential additional benefits of laser application. In the last 15 years, RCTs from several independent universities and systematic reviews (SR) clearly showed a similar efficacy in applying classical therapy (mechanical SRP) or laser, and no additional benefits in adding laser to mechanical treatment [4-7]. These findings suggest that caution must be taken with laser application for periodontal treatment, also considering 
the cost-benefit ratio [4-7]. In fact, as demonstrated approximately 15 years ago $[8,9]$, similar clinical and microbiological outcomes to those reported by Martelli et al. [1] may be easily achieved using conventional therapy, with significantly less costs. The reader should also keep in mind the long-term clinical efficacy of traditional periodontal therapy, which is supported by several studies with more than 10 years of follow-up [10, 11].

Finally, in the present study [1] the full-mouth treatment, meaning the treatment of all involved sites in the patient mouth, is not clearly defined, and this is another critical point, since patients were described by the authors as affected by "advanced" chronic or aggressive periodontitis.

\section{Follow-up}

The authors defined as a "long-term" observation the final 2year follow-up. This is another surprising aspect of this manuscript, since in periodontal literature the long-term effect of therapy is usually defined after at least 5 years of observation [12]. Conversely, the manuscript lacks critical information for the reader, including tooth loss (teeth extracted for advanced bone destruction) at final follow-up. The latter reflects the obvious primary treatment goal and the type of re-treatment of sites showing progression of periodontitis. Statistical analysis alone is not able to provide information related to prediction of disease progression and tooth loss at final follow-up. Furthermore, information regarding the secondary prevention of enrolled patients is unknown, even if authors generically reported the additional use of laser "only by teeth showing periodontal pockets with $P P D>2 \mathrm{~mm}$ ".

\section{Statistical analysis}

Surprisingly, the authors used a $t$-test for statistical analysis, which is not adequate in this type of study since multilevel analysis $[13,14]$ is generally used to assess the effect of prognostic factors on treatment outcomes. This approach allows the analysis of a multifaceted scenario that is non-surgical treatment of periodontal disease, where every variable is interconnected and able to influence each other at different levels.

\section{Ethics}

Although the authors reported that "there are no experiments requiring appropriate institutional review board(s) approval", it is surprising that no ethical board approval was reported, since the applied procedure is not a standard technique for the treatment of periodontal disease, and the clinical benefits are questionable.

Based on our criticisms, the manuscript conclusion "This study, conducted for the first time on such a large series, clearly demonstrates long-term efficacy of microbiologydriven non-invasive treatment of periodontal disease" is, in our opinion, erroneous since not supported by the applied methodology during the study. We do not believe that the present study provides useful clinical information in periodontal therapy.

Best regards

The board of the SIdP, Italian Society of Periodontology and Implantology

Claudio Gatti, President

Mario Aimetti Elected President

Giulio Rasperini Vice President

Luca Landi Treasurer

Francesco Cairo General Secretary

Open Access This article is distributed under the terms of the Creative Commons Attribution 4.0 International License (http:// creativecommons.org/licenses/by/4.0/), which permits unrestricted use, distribution, and reproduction in any medium, provided you give appropriate credit to the original author(s) and the source, provide a link to the Creative Commons license, and indicate if changes were made.

\section{References}

1. Martelli FS, Fanti E, Rosati C, Martelli M, Bacci G, Martelli ML, Medico E (2016) Long-term efficacy of microbiology-driven periodontal laser-assisted therapy. Eur J Clin Microbiol Infect Dis 35(3):423-431

2. Armitage GC (1999) Development of a classification system for periodontal diseases and conditions. Ann Periodontol 4(1):1-6

3. Amaliya A, Laine ML, Delanghe JR, Loos BG, Van Wijk AJ, Van der Velden U (2015) Java project on periodontal diseases: periodontal bone loss in relation to environmental and systemic conditions. J Clin Periodontol 42(4):325-332. doi:10.1111/jcpe.12381

4. Rotundo R, Nieri M, Cairo F, Franceschi D, Mervelt J, Bonaccini D, Esposito M, Pini Prato G (2010) Lack of adjunctive benefit of Er:YAG laser in non-surgical periodontal treatment: a randomized split-mouth clinical trial. J Clin Periodontol 37(6):526-533

5. Zhao Y, Yin Y, Tao L, Nie P, Tang Y, Zhu M (2014) Er:YAG laser versus scaling and root planing as alternative or adjuvant for chronic periodontitis treatment: a systematic review. J Clin Periodontol 41(11):1069-1079. doi:10.1111/jcpe.12304

6. Slot DE, Jorritsma KH, Cobb CM, Van der Weijden FA (2014) The effect of the thermal diode laser (wavelength $808-980 \mathrm{~nm}$ ) in nonsurgical periodontal therapy: a systematic review and meta-analysis. J Clin Periodontol 41(7):681-692. doi:10.1111/jcpe.12233

7. Sgolastra F, Severino M, Petrucci A, Gatto R, Monaco A (2014) $\mathrm{Nd}$ :YAG laser as an adjunctive treatment to nonsurgical periodontal therapy: a meta-analysis. Lasers Med Sci 29(3):887-895. doi:10.1007/s10103-013-1293-6

8. Ximénez-Fyvie LA, Haffajee AD, Som S, Thompson M, Torresyap G, Socransky SS (2000) The effect of repeated professional supragingival plaque removal on the composition of the supraand subgingival microbiota. J Clin Periodontol 27(9):637-647 
9. Cobb CM (2002) Clinical significance of non-surgical periodontal therapy: an evidence-based perspective of scaling and root planing. J Clin Periodontol 29(Suppl 2):6-16

10. Cattabriga M, Rotundo R, Muzzi L, Nieri M, Verrocchi G, Cairo F, Pini Prato G (2001) Retrospective evaluation of the influence of the interleukin-1 genotype on radiographic bone levels in treated periodontal patients over 10 years. J Periodontol 72(6):767-773

11. Axelsson P, Nyström B, Lindhe J (2004) The long-term effect of a plaque control program on tooth mortality, caries and periodontal disease in adults. Results after 30 years of maintenance. J Clin Periodontol 31(9):749-757
12. Kaldahl WB, Kalkwarf KL, Patil KD, Molvar MP, Dyer JK (1996) Long-term evaluation of periodontal therapy: I. Response to 4 therapeutic modalities. J Periodontol 67(2): 93-102

13. D'Aiuto F, Ready D, Parkar M, Tonetti MS (2005) Relative contribution of patient-, tooth-, and site-associated variability on the clinical outcomes of subgingival debridement. I. Probing depths. J Periodontol 76(3):398-405

14. Tomasi C, Leyland AH, Wennström JL (2007) Factors influencing the outcome of non-surgical periodontal treatment: a multilevel approach. J Clin Periodontol 34(8):682-690 